\title{
O contra-arquivo na arte: 0 poder xamânico de uma antropologia reversa
}

The counter-archive in art: The shamanic power of a reverse antropology

Melissa O. Rocha ${ }^{1}$ 


\section{Resumo}

Um presente ornado por traços surrealistas nos aproximam paulatinamente de uma realidade aparentemente distante, descrita nas profecias apocalípticas de crenças diversas. A superação da barbárie constitui-se na borda de um trajeto inalcançável. A retomada do terror se dá pelo estado de crise - geralmente simulado - na convocação de uma mudança radical por atores variados, não raramente invocando ações de violência sem precedentes contra um pensamento divergente, lavrando um terreno onde uma amnésia sobre as características de barbárie, convenientemente cultivada, floresce. A queda do céu, anunciada pela mitologia Yanomami, seria o cume desta jornada destinada ao declínio múltiplo dos sustentáculos civilizatórios, com seus vícios de origem que os fadam ao fracasso e que provocam, consequentemente, a derrocada indiscriminada aos coniventes e divergentes ao processo. $O$ texto se propõe a apresentar os trabalhos de artistas que se alinham com a discordância, produzindo obras, manifestos e denúncias dos abusos contidos no exercício do poder, seja na democracia ou no estado de exceção.

Palavras-chave: Arte política, arquivo, memória e violência.

\section{Abstract}

A present time adorned by surrealistic traits gradually brings us closer to a seemingly distant reality, described in the apocalyptic prophecies of diverse beliefs. The overcoming of barbarism is on the edge of an unreachable path. The resumption of terror is due to the state of crisis - usually simulated - in calling for a radical change by various actors, not infrequently invoking unprecedented acts of violence against a divergent thinking, plowing ground where an amnesia on the characteristics of barbarism, conveniently cultivated, blooms. The fall of the sky, announced by Yanomami mythology, would be the summit of this journey destined to the multiple decline of the civilizatory bases, with their vices of origin that fail them to the failure and that, consequently, they cause the indiscriminate collapse to the conniving and divergent ones to the process. The text aim to present the works of artists that align with the discordance, producing works, manifestos and denunciations of the abuses contained in the exercise of power, in democracy or in the exception state.

Keywords: Political art, achive, memory and violency. 


\section{Introdução: 0 arquivo ocidental e o caráter destrutivo às suas margens (homemxarquivo)}

A construção histórica é dedicada à memória dos sem nome.

Walter Benjamin

Acima de nós, avistamos a olho nu uma imensidão vazia, aparentemente preenchida apenas por pequenos corpos celestes, que se agigantam, quando avistados por lentes telescópicas, nos revelando a nossa insignificância existencial. A mirada cega, ao natural, para com as dimensões e elementos que habitam os horizontes sobre nossos ombros e também abaixo deles, desnuda a condição limitante de nossos sentidos perceptivos. Em diversos âmbitos, lançamos mão de mecanismos de expansão sensorial e intelectual, uma espécie de conjunto de próteses, que nos aproximam de um estado supra-humano, artificialmente produzido.

O papel é um exemplo de artefato engenhosamente concebido, como um instrumento relacionado a uma instância de poder, um repositório de ideias, memórias e ordens, um bastião utilizado pela civilização cristã ocidental, da qual a América Latina é uma filha mestiça e bastarda. A colonização ao longo dos séculos perseverou e se expandiu, apoiada sobre um punhado de letras estrangeiras ordenadas sobre o papel, proferidas em nome de autoridades humanas e ditas transcendentais. Nesta trajetória, esteve muito bem acompanhada de todo o terror necessário para restrição de desvios interpretativos e comportamentais a quem se colocasse no caminho, obstáculos tão indesejáveis nesta cruzada matemática das palavras, uma vez que se espera obediência pacífica.

O recorte do arquivo que aqui se propõe abriga sob sua égide uma coleção de evidências desta expedição civilizatória violenta e contínua sobre o solo latino - a margem/oriente -, em sua maioria, alimentada pelos proprietários da razão, os detentores dos papéis da lei e da fé. As legislações, crenças, narrativas, ideologias e conteúdos afins são legitimados por instituições que pertencem àqueles que, obviamente, dispõem do direito de mando e voz. O papel se consolidou, então, como instrumento de controle, um veículo dos comandos que regem mentes e corpos ao longo da História, uma prótese potente de uma estrutura constituinte de poder, onde o acesso e a validação plenos são disponíveis somente para poucos, o que reforça um aspecto dominante e excludente.

Derrida aponta que "seria este [ poder], na sua autoridade e pela força que dispõe, que indicaria um lugar e um domicílio para o arquivo, nos quais algo da ordem do segredo seria cultuado e preservado" (BIRMAN, 2008, p.115). Ao longo dos 21 anos percorridos pela recente democracia brasileira, a denominada Nova República, que se instituiu pelo processo de redemocratização em 1985, ilustrou com excelência o potencial destrutivo contido no ocultamento e na manipulação arquivista praticada pelos seus portadores. A opacidade dos fatos corresponde a uma ausência de memória, que segundo Derrida, constitui a medida da democracia, que se efetiva por este critério essencial: "a participação e o acesso ao arquivo, à sua constituição e à sua interpretação. Ao contrário, as ofensas à democracia se medem por aquilo que [...] chama Archives Interdites". (DERRIDA, 2001, p.16) 
Desde a instauração da Lei da Anistia (1979), reivindicada e atendida como Ampla Geral e Irrestrita, demoliu-se a possibilidade de edificação plena, pela via do Estado brasileiro e seus múltiplos braços, do direito à verdade e justiça ${ }^{1}$, além de tomar de assalto a jurisprudência para casos vindouros. Complementando essa conjuntura negativa, temos a Lei 11.111/05, uma inimiga notável para o êxito da Comissão $\mathrm{Na-}$ cional da Verdade, uma iniciativa já tardia de trazer à tona o chorume de ilegalidades que habitaram o período ditatorial. A referida lei prevê que o "acesso aos documentos públicos classificados no mais alto grau de sigilo poderá ser restringido por tempo indeterminado, ou até permanecer em eterno segredo, em defesa da soberania nacional" (PIOVESAN, 2010, p.14).

Esta amnésia imposta, e cuidadosamente conservada, isenta o repertório de "desastres que marcaram o fim do milênio passado" (DERRIDA, 2001, p.7), a que Derrida define como os arquivos do mal: "dissimulados ou destruídos, interditados, desviados, 'recalcados'. Seu tratamento é ao mesmo tempo massivo e refinado ao longo de guerras civis ou internacionais, de manipulações privadas ou secretas" (2001, p.7). Uma aplicação bem-sucedida deste procedimento foi o processo brasileiro de Justiça de Transição, uma pérola autoritária entre os demais países da América do Sul, uma vez em que permaneceu inexistente ou ridiculamente pontual, na medida em que se negou a realizar uma reparação adequada às vítimas do terrorismo de Estado e a penalizar os agentes da repressão, ao mesmo tempo em que foi conivente com o velamento democrático, agravado pela negligência do país para com as obrigações jurídicas internacionais relativas aos Direitos Humanos. Todos estes elementos contribuíram para uma formação conciliatória entre os gestores do poder e seus pares, deixando à parte a legalidade e a opinião pública, conduzindo o governo não para uma ruptura, mas para uma continuidade do estado de exceção e seus aparatos. Esse panorama configura no Brasil a vigência de uma aberração denominada "democracia de baixa intensidade"2 aliada a uma gestão social militarizada, como aponta Paulo Arantes, em entrevista.

\section{Desenvolvimento: 0 contra-arquivo, o poder xamânico da contra-antro- pologia (xamãxtranscendentalismo)}

Ainda sobrevive a sabedoria das selvas no seio das populações ameríndias, a prática e o conhecimento quanto às maneiras de atingir um estado supra-humano, de conexão com o invisível, que não perpassa a mercadoria. Enquanto as lentes telescópicas e, em menor escala, os óculos para uma visão deficiente, nos fornecem uma perspectiva visual que ultrapassa indiscriminadamente nossas capacidades naturais, no Brasil profundo este potencial é reservado e, brutalmente extrapolado, apenas àqueles que apresentam precocemente características que indicam uma inclinação inata para esta responsabilidade. O rompimento dos limites das capacidades físicas

\footnotetext{
1 Flávia Piovesan (2010) esclarece estes termos: "Tendo em vista a historicidade dos direitos humanos e considerando a fixação de parâmetros protetivos mínimos afetos à dignidade humana, com destaque à Declaração Universal de Direitos Humanos, destacam-se quatro direitos: o direito a não ser submetido à tortura; 0 direito à justiça (o direito à proteção judicial); o direito à verdade; e o direito à prestação jurisdicional efetiva, na hipótese de violação de direitos (direito a remédios efetivos).

2 Ver entrevista de Paulo Arantes: "Democracia de baixa intensidade militariza a gestão social" Disponível em: http://www.boitempoeditorial.com.br/v3/news/ view/3549 Acesso em: 08 Jun 2016
} 
se dá na interação direta com uma simples mistura do que a terra fornece em seu estado bruto, mas condicionalmente, se efetiva mediante um processo iniciático e ritualístico metódico. Ao xamã, reserva-se a posição de porta-voz, o vetor pelo qual acessa-se o conhecimento invisível aos olhos vulgares.

O pó yãkoana, produzido a partir da mescla de resina da árvore yãkoana hi com outros elementos ${ }^{3}$, é ingerido por inalação, e após o uso sistemático em rituais, dará ao xamã o acesso aos espíritos xapiri, os sábios portadores dos mistérios da natureza. O xamã Yanomami Davi Kopenawa em "A Queda do Céu" esclarece: "Os espíritos são invisíveis para seus olhos de fantasma [...]. Apenas os xamãs são capazes de contemplar os xapiri, pois tornados outros com a yãkoana, podem também vê-los com olhos de espíritos" (KOPENAWA, 2015, p.118). Portanto, os apartados do acesso direto aos xapiri, seriam os denominados "olhos de fantasma", uma vez que veem apenas a "aparência enganosa dos seres e dos fenômenos" (KOPENAWA, 2015, p.615) enquanto a visão xamânica, "dá acesso à imagem-essência dos entes" (Ibid).

Desta maneira, o xamã detém através de uma expansão da consciência, o ingresso a uma plataforma transcendente de lucidez, onde um conhecimento pleno superior poderá lhe ser repassado indefinidamente ${ }^{4}$. Por esta via, torna-se possível uma aproximação do poder xamânico, enquanto um receptáculo e também transmissor da mensagem, à posição dos arcontes, sendo que estes não são somente guardiões dos arquivos, mas também autorizados a interpretá-los, de forma que sob sua guarda, "estes documentos diziam, de fato, a lei; eles evocavam a lei e convocavam à lei" (DERRIDA, 2001, p.12-3).

O xamã partilha com os arcontes os papéis de protetor, intérprete e líder, contudo, carrega diferenças cruciais da condição arcôntica apontada por Derrida, na qual a chave de atuação reside na restrição seletiva e não na democratização total. Assim, consolida-se o estatuto de contra-arquivo das mensagens xamânicas por duas vias: primeiro, pelo dever de compartilhá-las e segundo, pelo teor subversivo, de resistência do seu discurso, pois clama pela defesa da natureza e pela busca por uma harmonização dos recursos naturais do planeta, promovendo uma clara oposição ao sistema vigente, o portador do arquivo hegemônico, de uma agenda vitoriosa de desequilíbrio e exploração predatória.

O olhar contra-antropológico empenhado por Davi Kopenawa lhe permite tecer duras críticas à ganância dos homens da mercadoria, o povo nape, um termo Yanomami para referir-se aos "brancos", mas que na realidade corresponde a pessoas de qualquer etnia em busca da destruição da autonomia da população nativa, ou seja, "o Outro, o inimigo por excelência" (CASTRO, 2015, p.12). Pelas palavras do xamã, o prenúncio apocalíptico se aproxima:

A floresta está viva. Só vai morrer se os brancos insistirem em destruí-la. Se conseguirem os rios vão desaparecer debaixo da terra, o chão vai se desfazer, as árvores vão murchar e as pedras vão rachar no calor. Os xamãs[...] não serão capazes de espantar as fumaças de epidemia que nos devora, [...] conter os seres maléficos que transformam a floresta num caos. Então morreremos, um atrás do outro, tanto os brancos quanto nós. Todos os xamãs vão acabar morrendo. Quan-

3 Folhas secas pulverizadas de maxara hana, cinzas de cascas das arvores ama hi e amatha hi (ver ALBERT\&MILLIKEN, 2009,p.114-6)

4 As palavras dos espíritos xapiris são muito antigas, mas são sempre renovadas através dos xamãs e "assim tem sido há muito tempo, sem fim" (KOPENAWA, 2001, p.74) 
do não houver mais nenhum deles vivo para sustentar o céu, ele vai desabar. (KOPENAWA, 2015, p.6)

O extenso depoimento de Kopenawa, em $A$ queda do céu é um trabalho pioneiro que procura elaborar uma antropologia simétrica, uma tentativa de que a voz subalterna seja ouvida, de que uma reflexão deslocada do centro opere a conscientização dos brancos dotados de uma cabeça "cheias de esquecimento". Este ponto em questão, fundamentalmente exaltado pelo xamã, condensa as "patologias de comunicação" que afetam especialmente os brancos: a desmemória, "a surdez, cegueira e a língua de espectro (incompreensível) " (VIVEIROS, 2015, p.15). E também alerta que estas doenças podem afetar também os Yanomami, cegos ao mundo dos xapiri e seduzidos pelas mercadorias dos nape.

O esquecimento como atributo especial do branco, faz com que sejam necessários o uso de apêndices, para mitigar a amnésia. As "peles de papel" e as "peles de imagem" são as próteses descritas por Kopenawa, que na sua leitura contra-antropológica, não apenas remediam essa patologia como carregam em si, o poder de convencimento. Enquanto os Yanomami mantêm as palavras dos xapiri gravadas profundamente em seu pensamento, alimentadas ininterruptamente pela comunicação garantida pelos xamãs desde tempos imemoriais, conservando-as a salvo da água, do fogo e do envelhecimento, os brancos transferem a integridade do conhecimento para os documentos físicos ou virtuais, as chamadas peles, por Kopenawa. Verifica-se assim, uma atrofia do sensível, uma certa subutilização dos sentidos e capacidades na dita sociedade civilizada, em que codifica-se, altera-se e arquiva-se a memória sob a tutela de órgãos governamentais, de segurança, museus e bibliotecas, privando-a do compartilhamento direto. Kopenawa utiliza-se então, da respeitabilidade devotada ao suporte para repassar a palavra: "Eu, um yanomami, dou a vocês, os brancos, esta pele de imagem que é minha". (KOPENAWA, 2015, p.66). Por esse aspecto, reforça-se o caráter de arkhê destas peles, como o lugar de origem e da ordem, ao que Derrida denomina como "o princípio da natureza ou da história, ali onde as coisas começam - princípio físico, histórico ou ontológico -, mas também o princípio da lei ali onde os homens e os deuses comandam, ali onde se exerce a autoridade, a ordem social" (DERRIDA, 2001, p.11).

Davi Kopenawa e Ailton Krenak são importantes líderes indígenas que tratam de jogar luz na sombra do esquecimento. Em 1987, na ocasião da Assembleia Constituinte pela defesa da Emenda Popular da União das Nações Indígenas, Aílton foi responsável por um discurso emblemático na tribuna do Congresso Nacional, no qual proferiu denúncias relativas ao desrespeito dos direitos indígenas e nos lembrou, com os olhos marejados, que o sangue indígena rega diariamente os 8 milhões de hectares de extensão do país. Simultaneamente ao seu discurso, Aílton cobria sua face com pasta de jenipapo, deixando-a completamente negra, em luto. Os indígenas, ao contrário dos brancos, não possuem o esquecimento como alternativa. 


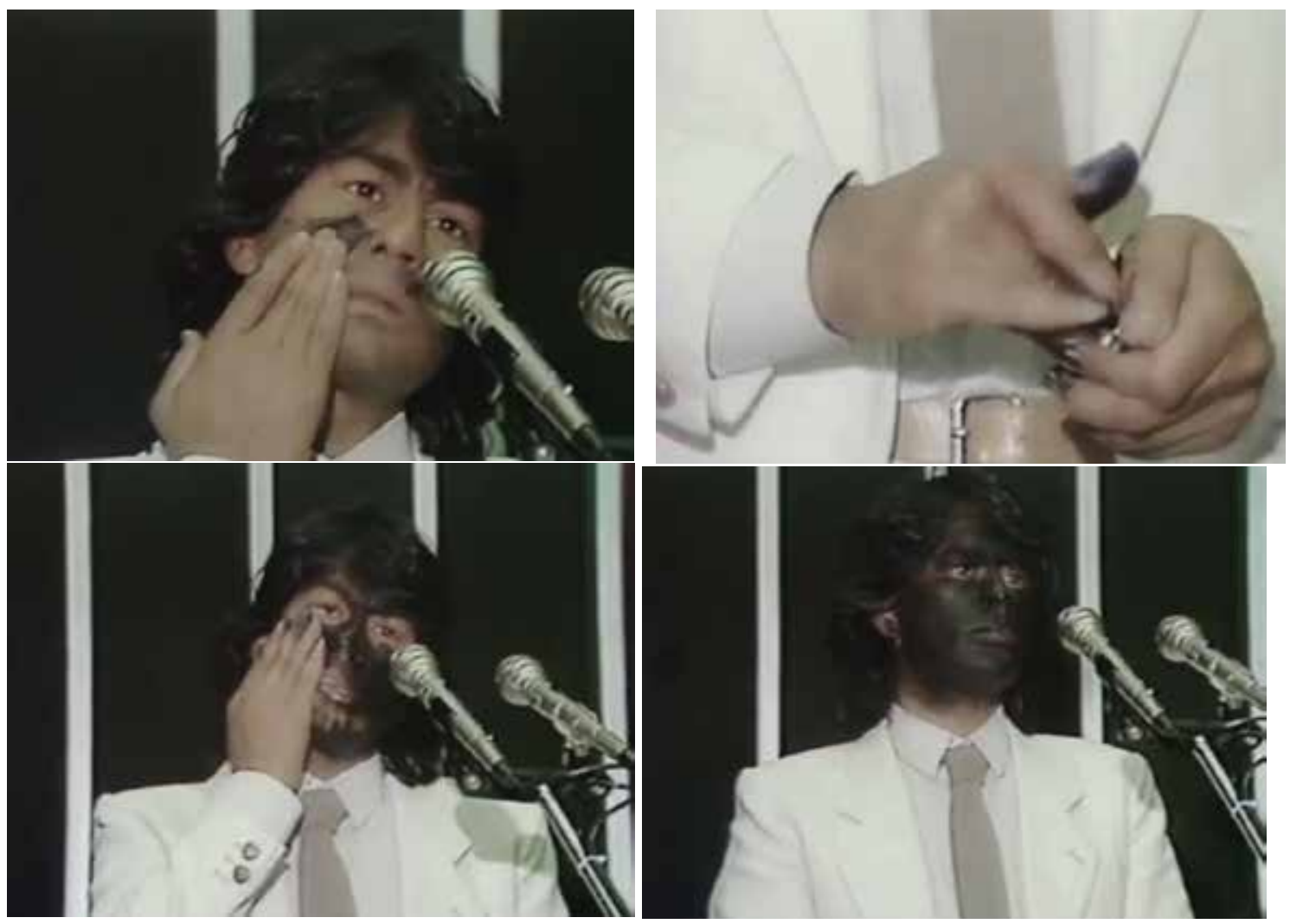

FIG 1 - Ailton Krenak na Assembléia Constituinte de 1987(montagem still de video 4 fotos). Fonte: Canal Indio Cidadão Youtube. Acesso em 09 mai. 2017.

A fronteira extrativista e missionária foram frentes permanentes de contato e avanço pelo território Yanomami que coexistiram até a década de 1970. Após esse período as terras foram alvo do Plano de Integração Nacional instituído pelos militares que dentre suas ações estava a abertura da estrada Perimetral Norte (1973-76) e programas de colonização pública (1978-79). A existência de jazidas minerais pelo RADAM (projeto de levantamento de recursos amazônicos) surge como agravante, gerando um intenso assédio de garimpeiros intensificada na década de 1980, configurando uma espécie de corrida pelo ouro a partir de 1987.

Como um reflexo destes acontecimentos, Missão/Missões de Cildo Meireles (1987) introduz de maneira didática a representação simbólica dos elementos envolvidos no processo colonizador. O trabalho situa-se em uma sala escura com iluminação localizada. Por entre cortinas negras, avista-se no chão, em formato retangular, aproximadamente 600.000 moedas dispostas uniformemente. Do centro deste retângulo ergue-se uma coluna de hóstias que encontra no teto uma coleção de ossadas, como lustres que pendem do teto.

Da poderosa conjunção de símbolos eleitos pelo artista, a hóstia e o dinheiro sintetizam frentes históricas que há muito produzem e/ou justificam o elemento morte, que completa a tríade. A religião e o poder econômico foram duas forças que atuaram em parceria para consolidar um dos maiores genocídios da humanidade. 


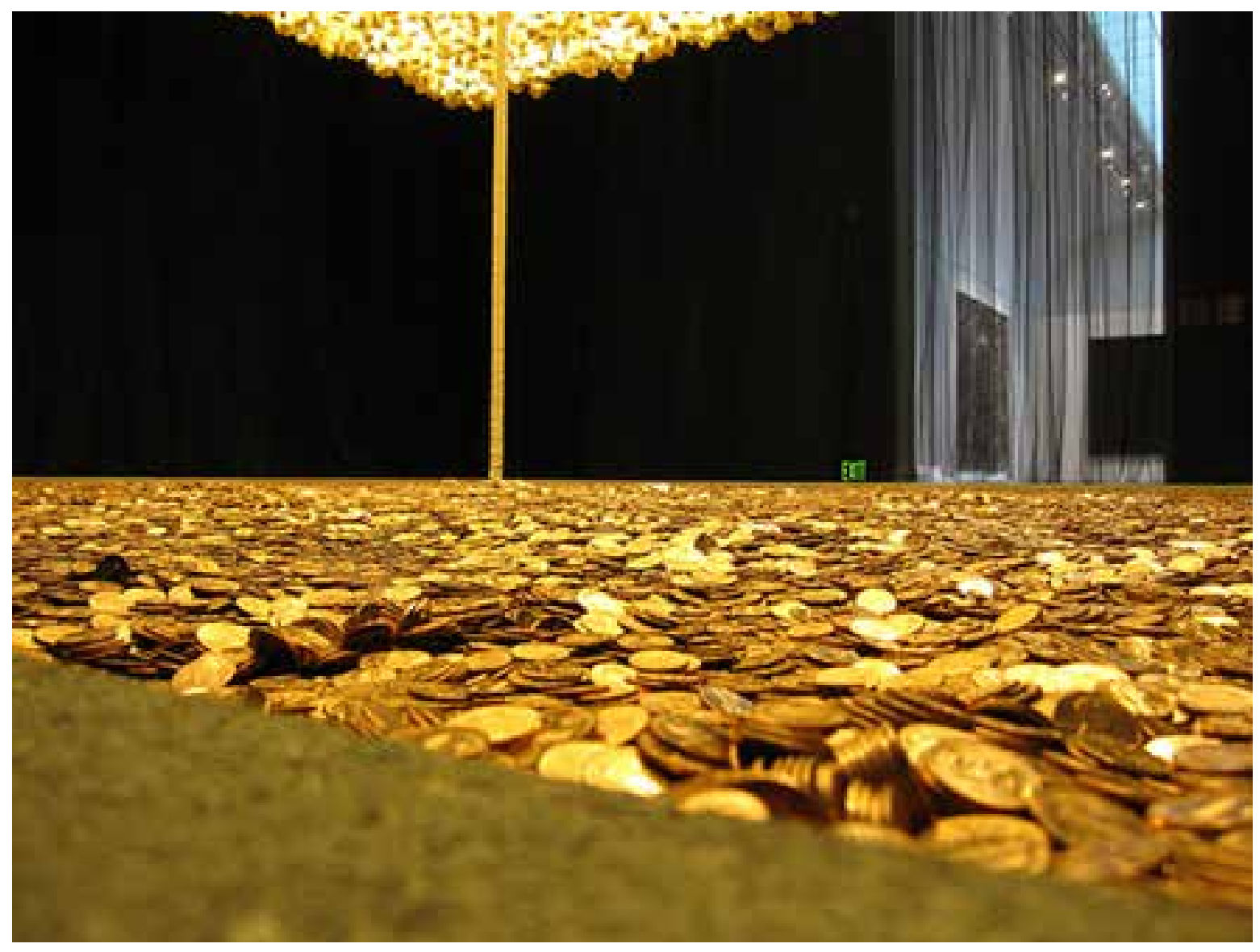

FIG 2 - Cildo Meireles, Missão/Missões, 1987. Disponivel em: https://izzyspada.files.wordpress.com/2013/04/4277337000_cd1e995615.jpg Acesso em 09 mai. 2017.

A continuidade dos massacres de vastas populações e povos indígenas deu seguimento ao projeto colonizador/conquistador do território haja vista que, desde a chegada dos europeus, as guerras declaradas aos nativos e os decretos de etnocídio tiveram como consequência desaparecimento de mais de cinco milhões de indígenas que viviam no atual território brasileiro. Os ameríndios e sua ocupação saudável da terra sempre foram tidos como entraves ao projeto desenvolvimentista por impedir o acesso do capital às suas fontes de água límpidas, terra fértil e subsolo rico em metais:

Historicamente, na América Latina, a fixação das fronteiras nacionais veio acompanhada de políticas sistemáticas de exclusão e extermínio dos povos indígenas, que foram suprimidos de qualquer projeto de unificação nacional. Na etapa atual, quando os processos de globalização abalam as estruturas dos Estados-nação em todo o planeta, instala-se na região a dúvida sobre a viabilidade dos planos de inclusão de populações que foram marginalizadas ao longo de vários séculos. (CIIIP, 2002, p. 148)

Avançando sobre o ano que antecede a ditadura, documentos oficiais do Congresso Nacional atestavam, que em 1963 havia no país em torno de 300 mil índios e, segundo Marcelo Zelic, vice-presidente do Grupo Tortura Nunca Mais de São Paulo, em 1968 essa população cai rigorosamente para 80 mil. Encontram-se registradas em documentos reunidos pelas entidades Associação Juízes para a Democracia, Comissão Justiça e Paz da Arquidiocese de São Paulo, Grupo Tortura Nunca Mais e o site Armazém Memória, as maneiras em que ocorreram o desaparecimento de 220 mil pessoas. O relatório Figueiredo (1968), por exemplo, possui mais de 7 mil páginas de denúncias. 
Os recursos de sabotagem e deslegitimação da luta indígena se acirraram durante o regime militar pelo uso malicioso da legislação e do poder. O ministro do Interior, Maurício Rangel Reis lançou um projeto na ocasião, que através da falsa intenção de emancipar o índio, na verdade o jogava na condição de cidadão comum, sem direito algum sobre suas terras ocupadas, que seriam entregues aos latifundiários: "ao invés de demarcar todas as terras indígenas até 1978, como previa o Estatuto do Índio (Lei 6.001, vigente até hoje), resolveria o problema declarando $80 \%$ dos índios como não índios".

Além disso, foram criados nas décadas de 1960 e 1970, o Reformatório Agrícola Indígena Krenak (Resplendor-MG) e a Fazenda Guarani (Serra do Cipó-MG), dois centros de detenção de índios que apontam apenas para algumas das frentes punitivas e de vigilância dos anos de chumbo. Os indígenas além de vítimas, também acabaram por serem recrutados pelas Forças Armadas: formou-se uma polícia indígena que passou por um processo de formação militar para que esses novos agentes policiais retornassem às suas etnias de origem, colaborando com a ordem das aldeias. Foram instaladas Guardas Rurais Indígenas (GRINs) em Goiás, Mato Grosso, Maranhão e Minas Gerais.

Há pouco mais de cinco anos, a pesquisa de Zelic para a Comissão Nacional da Verdade revelou o vídeo "Arara" que contém registros desse projeto perverso e malsucedido da política indigenista de nosso país. A formatura que ocorreu em novembro de 1969 na cidade de Belo Horizonte foi documentada pelo fotógrafo e cinegrafista alemão Jesco von Puttkammer (1919-94), mostra os índios em exercícios de luta, fardados e, em certo momento muito aplaudidos por uma gama de generais e militares, ao exibirem a tortura aplicada nos presos políticos no pau de arara. A festividade compunha a formatura dos indígenas que, três anos após retornarem para os seus, demonstraram o fracasso da operação ao manifestarem comportamento violento através de espancamentos, estupros e roubos como os ocorridos na Iha do Bananal habitada pelos Karajás.

A sociedade civil brasileira, ora surpresa, ora conivente, recebeu tardiamente informações mais completas do massacre de incalculável número de vítimas promovido pelo Estado, na ocasião da descoberta acidental pela Comissão Nacional da Verdade do escandaloso Relatório Figueiredo, que estava supostamente desaparecido e acabou por reaparecer convenientemente, no lixo do Museu do Índio, no Rio de Janeiro, em 2013. O autor, o procurador Jader de Figueiredo Correia, elaborou a pedido do extinto Ministério dos Interiores em 1967, um minucioso compilado de arquivos com documentos e registros de abusos e genocídios contra a população indígena perpetrados pelo SPI (Serviço de Proteção ao Índio) e pelos latifundiários, entre as décadas de 1940, 50 e também durante o regime militar.

Entre as imagens mais marcantes destes arquivos, estava a fotografia de uma índia amarrada de ponta cabeça diante de seus dois algozes. O relato sinaliza que o crime teria ocorrido a mando de ruralistas contra a tribo Cinta Larga, situada na região próxima à fronteira dos estados de Rondônia e Mato Grosso, e que após assassinarem seu filho, partiram o corpo da nativa ao meio. Segundo o relatório, os assassinos caminhavam tranquilamente pelas ruas de Cuiabá, sendo que um deles encontrava-se vendendo sorvete para as crianças, sem que a polícia o incomodasse. 
Sobre o método adotado, Figueiredo descreveu brevemente: "os mateiros os caçam a tiros de metralhadoras e racham vivos, a facão, do púbis para a cabeça, o sobrevivente" (Relatório Figueiredo, p.7) ${ }^{5}$.

O corpo latino, seja ele nativo ou mestiço, esteve especialmente entre os anos de 1960 e 80, mergulhado no obscurantismo das incertezas quanto ao regimento dos seus limites e liberdades no espaço político, social e artístico. A imagem do corpo dependurado foi evocada na performance proposta por Daniel Santiago em 1982, na qual o artista pernambucano reproduz, pelo gesto, a violência expedida aos diversos indivíduos torturados que não se cessaria ao fim da ditadura. Em suas mãos, o cartaz O Brasil é o meu abismo, localiza geograficamente a profundidade abissal de nossa cova, na qual enterram-se periodicamente, nossa dignidade, cadáveres e direitos.

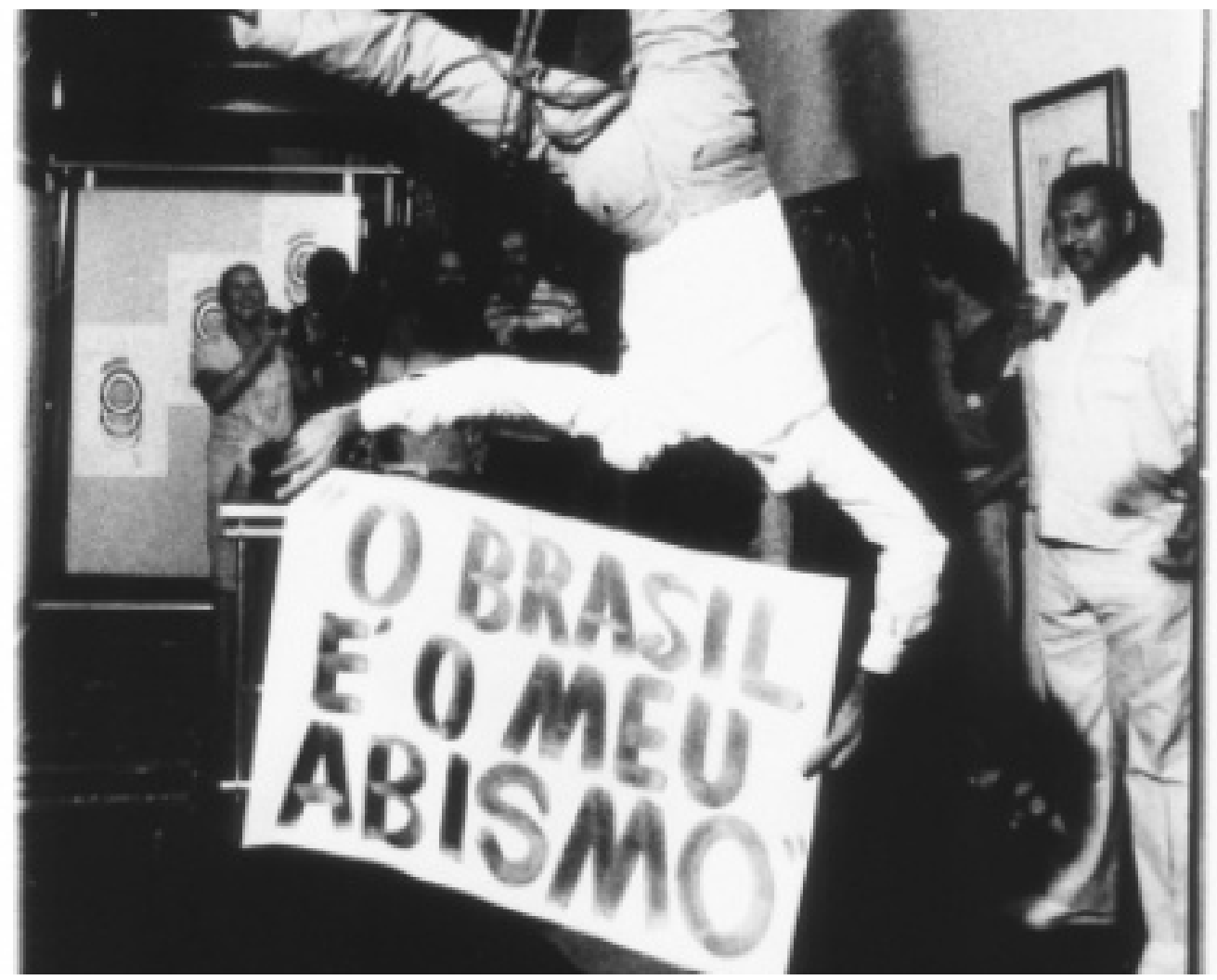

FIG 3 - Daniel Santiago. O Brasil é o meu abismo, 1982. Registro de performance. Fonte: http://www.cultura.rj.gov.br/materias/caravana-de-vanguarda-nordestina. Acesso em 09 mai. 2017.

Da mesma forma que segue perfeitamente atual a postura crítica e o gesto de Aílton Krenak retomados pelo indígena Almires Martins, no filme de Armando Queiróz, intitulado Ymá Nhandehetama (2009) - termo que significa "antigamente fomos muitos" na língua guarani -, e que foi exibido na 31a Bienal de São Paulo (2014). Sob o tom azulado do vídeo, Almires denuncia o apagamento do índio enquanto um cidadão de direitos, em detrimento da exaltação da imagem idílica, silenciosa, pacífica, do corpo nu sedutor e selvagem, bem adequado à propaganda turística para "inglês ver". 


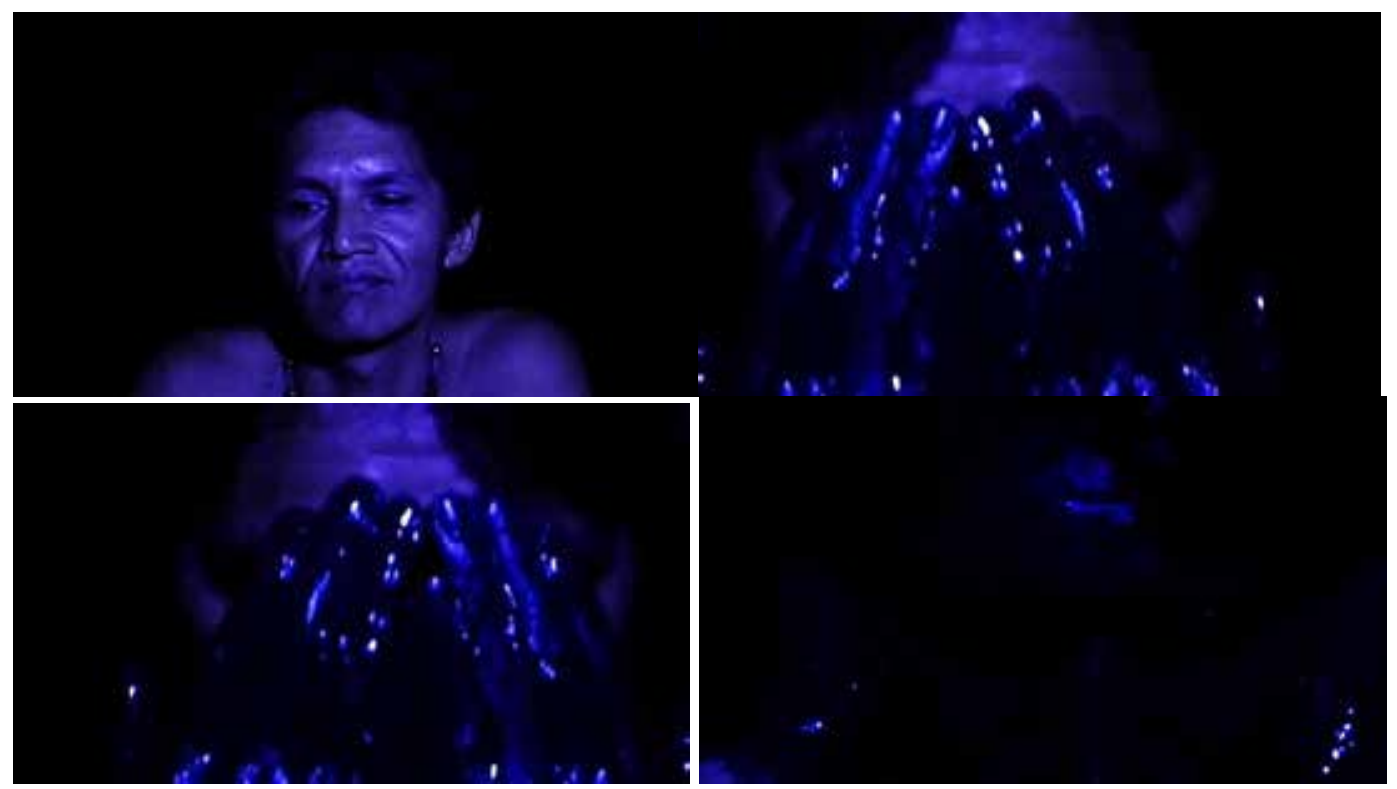

FIG 4-Almires Martins, Ymá Nhandehetama (2009). Still de vídeo. Fonte: Canal IMAGETICAFILMS no youtube. Acesso em 09 mai. 2017.

Apagamento este, segundo o guarani Almires, perpetrado por frentes diversas, pelas autoridades políticas, a oligarquia, a mídia e a academia, todos investidores vorazes nessa invisibilidade, no sequestro da voz indígena que fala somente através do Outro audível, o branco. Ao terminar sua fala, por aproximadamente um minuto de silêncio, observamos seu olhar voltado para baixo, provavelmente a manipular algo em suas mãos, que em seguida se ergue enegrecida, embebida com o pigmento depositado melancolicamente em sua face, até que sua presença desapareça completamente, fundindo-a ao invisível, uma condição muito similar à indiferença generalizada para com a violência e o desaparecimento do seu povo.

$\mathrm{Na}$ trilha contraditória da garantia de direitos das minorias étnicas, proliferavam nas bancas de jornais, durante a ditadura, cartões postais que retratavam a cultura e o estilo de vida indígena. Influenciada por esta disseminação a obra Brasil Nativo/ Brasil Alienígena é composta por esses cartões postais organizados em duas colunas de imagens: à esquerda situavam-se os postais turísticos apropriados por Anna Bella Geiger e à direita, dispunham-se as mesmas cenas, refeitas em foto-performances. Geiger problematizou tanto a condição dessa persona originária das matas tropicais, quanto a imagem da mulher moderna, resultante de diversas imigrações/miscigenações consecutivas ao longo de nossa história. A artista reproduz estas imagens mediante sua atuação ante a câmera fotográfica, em uma postura etnográfica, com seus artefatos locais/urbanos a subserviência ideal retratada nas imagens dos nativos:

Se em "Brasil nativo/Brasil alienígena", ao repetir com aparente obediência os gestos dos indígenas dos cartões-postais, Geiger atesta a impossibilidade de ser o outro (aquele outro, assumido como símbolo do coletivo), ao inserir sua imagem nas fotos de divulgação protagonizadas por artistas homens respeitados do circuito internacional, ela - aparentemente reiterando os valores simbólicos daquelas imagens paradigmáticas do artista entendido como "gênio" - desvenda os esquemas ficcionais, ideológicos, daquelas imagens. (CHIARELLI, 2007, p.84) 


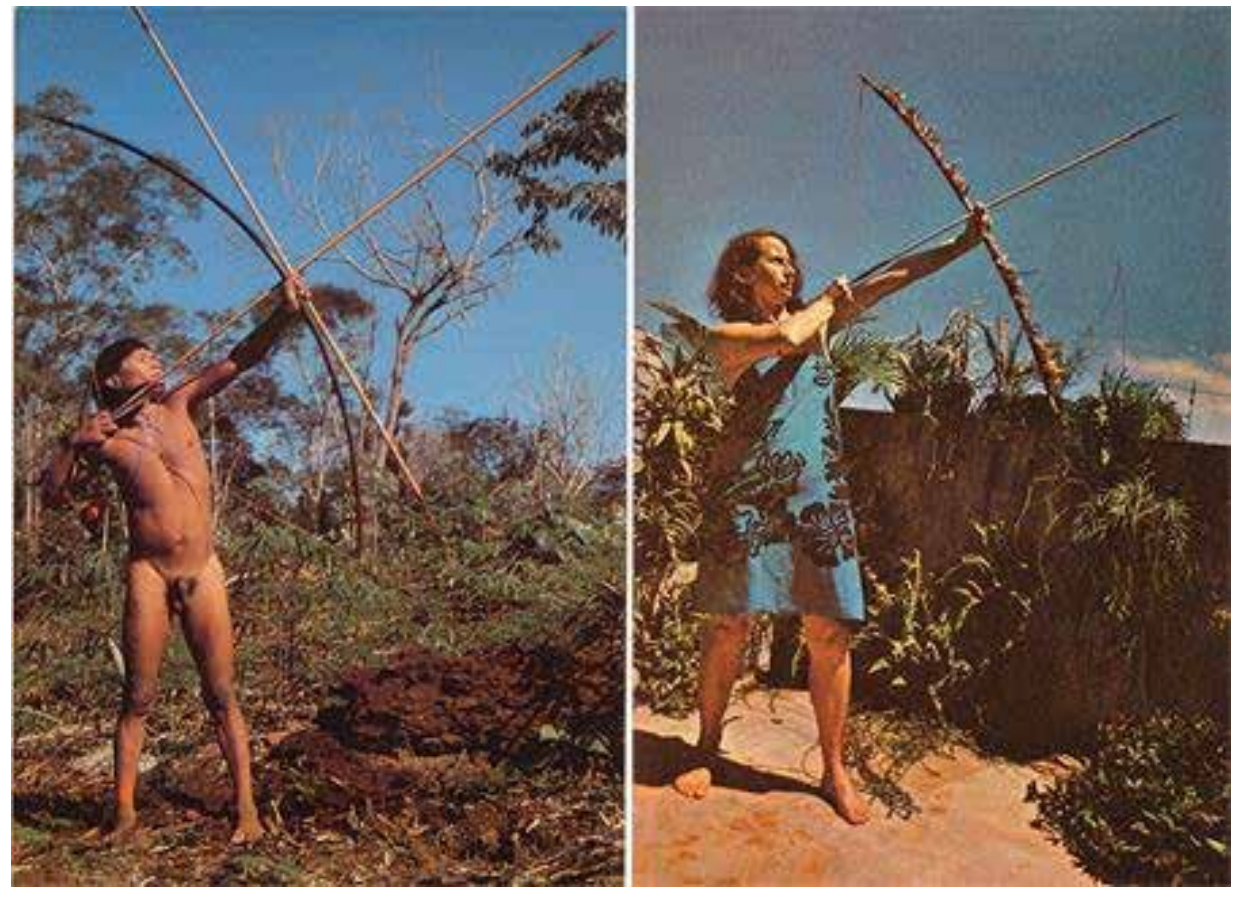

FIG. 5. Anna Bella Geiger, Brasil Nativo/ Brasil alienígena, 1977 (série de 9 pares). Disponível em: http://asombradofuturo.org/images/c/ce/ Annabella.jpg Acesso em 09 mai. 2017.

O trabalho concentra mulheres e indígenas, em um mesmo lócus problemático, marginal, objetificado e, de vários modos, "estrangeiros" em seu próprio país. 0 feminino representado profusamente nos meios de comunicação como um corpo desejado, construído a partir de estatutos ideais de beleza e comportamento, pelo qual pretende-se controlá-lo, é também amplamente vulgarizado ao ser submetido a uma posição de chamarisco decorativo de vendas. Enquanto isso, a fetichização do indígena, que busca promover o seu status de pureza e bucolismo, é na verdade a imagem exportada de um Brasil inexistente.

A imagem indígena se ajusta nas medidas fictícias da publicidade, mas é constantemente expelida do corpo social tal qual a obra de Anna Bella que reproduziu estas imagens idealizadas, atuando ante a câmera fotográfica, a partir de seus artefatos locais/urbanos evidenciando o quão estranho e distante da sociedade estava aquela população e sua cultura, retratada nas bucólicas fotos dos nativos. Brasil Nativo/Brasil Alienígena (1977) explicita o papel ornamental do índio, apresentando-os como objeto de estudo antropológico, quase um exemplar de um Gabinete de Curiosidades, alimentado por essa desidentificação social, que lhe priva de sua cidadania.

De maneira a registrar as dissonâncias do período, que com uma mão coloca a imagem ameríndia como valor nacional e outra o extermina impiedosamente, em 1975, estava presente na 13ª Bienal de São Paulo o jovem cacique Xingu Aritana. A imagem do índio cumprimentado pelo então presidente General Ernesto Geisel ilustrou a manchete do Jornal da Tarde e mostrava um índio alegre em suas roupas ocidentais, junto a um senhor sorridente e sua esposa. Geisel em seu governo instituiu o Estatuto do Índio, de 1973, que propunha "integrar e emancipar rapidamente o indígena promovendo inclusive, a implantação de projetos de desenvolvimento 
econômico em suas terras." Um texto generoso, que previa inclusive a demarcação de terras em, no máximo cinco anos. Obviamente por trás de toda a bondade e dignidade proposta estavam outros interesses: a intenção de liberar o desenvolvimento econômico da Amazônia e demais áreas ocupadas consideradas como fundamentais para a economia crescente brasileira.

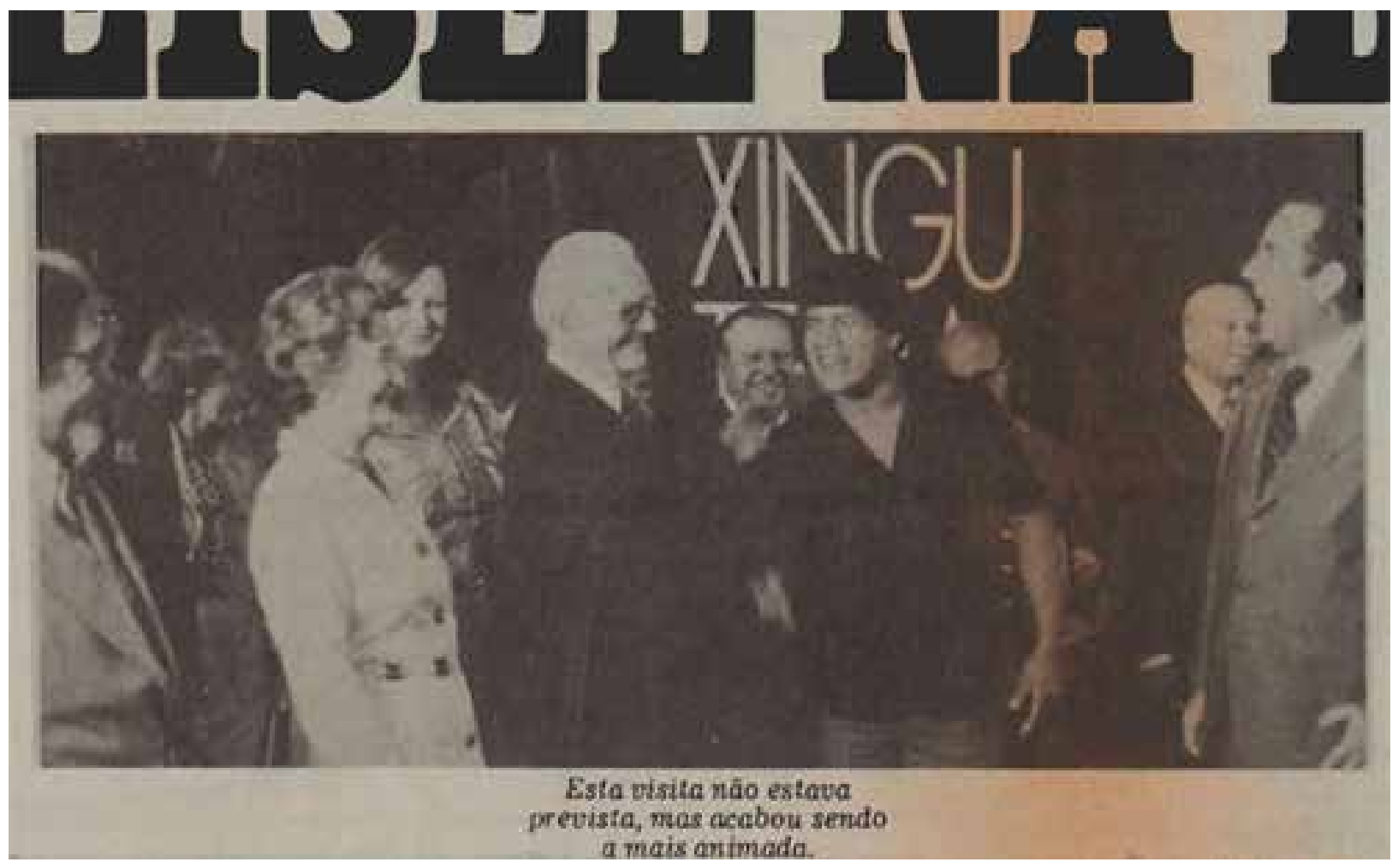

FIG. 6 - General Ernesto Geisel cumprimenta o cacique Aritana, na 13a Bienal de São Paulo. 01 nov. 1975. Fonte: Fundação Bienal de São Paulo.

$\mathrm{Na}$ exposição, Aritana se responsabilizou por reproduzir o ambiente das ocas indígenas no Pavilhão Xingu e esteve pessoalmente presente durante toda a mostra. Descrito pela reportagem no Estado de São Paulo como "discreto, tímido, olhar vivo, muito inteligente, ele faz questão de ver e ouvir tudo o que dizem a seu redor", o jovem cacique sentiu a arte da mostra sem significação, sem nada para dizer. Em seu pavilhão, além do cacique e da reconstituição do seu meio ambiente, havia a coleção de arte indígena dos irmãos Villas Bôas e fotografias de Maureen Bisiliat. Curiosamente, apesar de mencionado no texto de apresentação da exposição, não há mais nada sobre isso no catálogo da Bienal.

$\mathrm{Na}$ época da exposição a discussão crítica perpassava o discurso da "arte pela arte" frente à uma "arte política", no entanto, pouco até hoje foi discutido no que concerne a uma visão madura tanto da arte desses povos quanto à sua cultura. No Brasil, a arte indígena faz parte de uma história passada e primitiva. Seus artífices se encontram nas praças das cidades, onde nas ruas, seu valor é subestimado, além de serem comuns relatos dos mais variados tipos de violência.

Diferente dos registros de denúncia, o trabalho de identificação realizado por Claudia Andujar aproxima-se dos indígenas, mas de maneira completamente diversa. Em Marcados (1981 -83), a artista adentra os rincões amazônicos sob demanda de 
trabalho ${ }^{6}$. A série de fotografias efetivou-se como instrumento de monitoramento e estudo das condições de saúde dos indígenas que estiveram em contato com os brancos. A catalogação destinada ao controle de vacinação dos nativos e para tratos de futuras demarcações, retratou faces variadas dos Yanomami. O trabalho, que possui caráter positivo, ainda que em um contexto político delicado para as populações indígenas, não foi capaz de esconder o potencial destrutivo de instituições diversas, perpetrado pelo vilipêndio de direitos e extermínios de populações nativas, em nome da expansão e ocupação da porção oriental do país. Seriam desnecessárias medidas como a vacinação, se as demarcações das terras fossem estabelecidas e respeitadas de antemão.

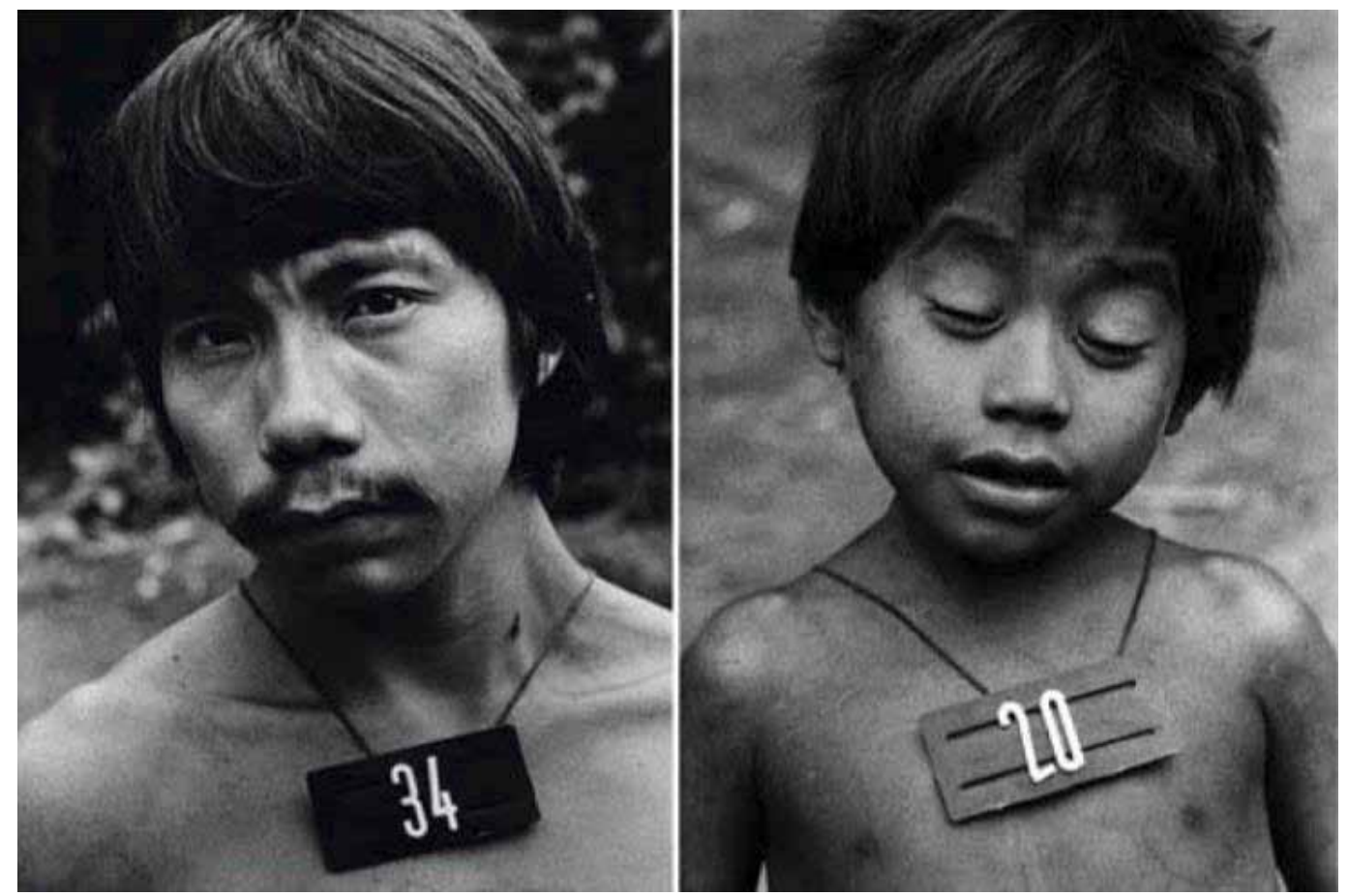

FIG 7 - Cláudia Andujar, Série Marcados, 1891-83. Fonte: Catálogo Marcados, Cláudia Andujar

A semelhança com que se configuram a representação dos indígenas com a catalogação empregada em diversos outros processos de dominação são evidentes. Durante o século XIX, procedimentos de inventário, arquivamento e submissão simbólica representaram segundo André Rouillé, "a conquista integral do visível" na qual a fotografia-documento contribui também para a expansão do "espaço de trocas, para a dilatação dos mercados, para o alargamento da zona de intervenções militares ocidentais" (ROUILLÉ, 2009, p. 99).

A identidade, mecanismo inventado pelo mundo branco, é aplicada nesta ação através do registro frontal e pela numeração. Os membros da etnia Yanomami tradicionalmente não possuem nomes próprios, mas atendem por uma característica ou atributo mais marcantes de sua personalidade. São comuns as situações em que o direito de ir e vir dos indígenas são violados, por não portarem documentos de identificação, haja vista a dificuldade de fazê-lo, já que a maioria deles não possuem certidão de nascimento. Para que possam se deslocar em distâncias maiores ou viagens

6 Grupo de trabalho que contava com a participação de Claudia Andujar (coordenadora da Comissão pela Criação do parque Yanomami - CCPY) mais dois médicos patrocinado pela organização dinamarquesa IGWA - International Workgroup for Indigenous Affairs). 
de avião, por exemplo, portam uma autorização da Funai que lhes salvaguarda o direito, mas que no terreno burocrático desinformado, acaba por não ser o suficiente.

Nas fotografias de Andujar, vemos cada índio retratado com uma pequena placa pendurada em seu pescoço, na qual continha um número de identificação. Eles foram assim marcados, reduzidos aos dados estatísticos, como parte de um legado recorrente aos corpos subjugados pelo poder. De certa maneira, nesta ação de documentação dos membros da tribo Yanomami reside uma ambivalência: o procedimento majoritariamente atribuído ao contexto de controle, das prisões, dos campos de concentração, da morte, todavia aqui, suas marcas produzidas se destinam a salvar vidas. Esta tribo, entre outras sacrificadas, foi selecionada para sobreviver.

Cláudia Andujar esteve intimamente relacionada à luta dos povos indígenas, viveu por quase dez anos entre Roraima e Amazonas próxima aos Yanomamis até ser enquadrada na lei de Segurança Nacional pelo governo militar e ser expulsa do território indígena pela Funai em 1978 por ser testemunha dos massacres no período. Juntamente com o antropólogo francês Bruce Albert criou a organização não-governamental Comissão Pela Criação do Parque Yanomami (CCPY, hoje Comissão Pró-Yanomami).

Da relação de convivência e apoio com estas populações surgiu uma parceria frutífera entre Cláudia, Bruce e Davi Kopenawa, este último estimulado pelas inciativas da dupla a se engajar na liderança atuante de sua população. Em 2016, Dario Yawarioma, filho de Kopenawa, prestou homenagens à fotógrafa no documentário "A Estrangeira" (2015) na Universidade Federal de Roraima dando vistas à relevância e cumplicidade autêntica com essa etnia: "Estou fazendo parte da história de 40 anos de convivência dela na Terra Indígena Yanomami. Eu tenho muito orgulho de homenagear minha segunda mãe!"7.

Outros artistas que se dedicaram à causa indígena produziram algum impacto, ainda que reduzido, na amplificação destas vozes em anos anteriores. A proximidade com que Cildo Meireles lidou com a questão se deu a partir de seu pai, que trabalhou diretamente na elaboração de um dossiê sobre o massacre dos índios Kraôs, no norte de Goiás e que o influenciou na concepção de algumas obras, entre elas, Zero Cruzeiro (1974), que parte daquilo que o artista define como Inserções em Circuitos Antropológicos, onde é representada na frente de notas de dinheiro a imagem do índio e no seu verso, a de um louco. Cildo demonstra precisamente, através da indicação monetária, a ausência de valor e o posicionamento marginal conferido a esses corpos. Novamente, observamos a pertinência do trabalho sobreviver ao curso dos anos, resultando em sua reedição pelo artista, como Zero Real, em 2013.

7 Relato do evento e declaração disponível em: http://amazoniareal.com.br/testemunha-de-massacre-contra-os-yanomami-claudia-andujar-e-homenageada-em-roraima/ Acesso em: 12 mai 2017. 

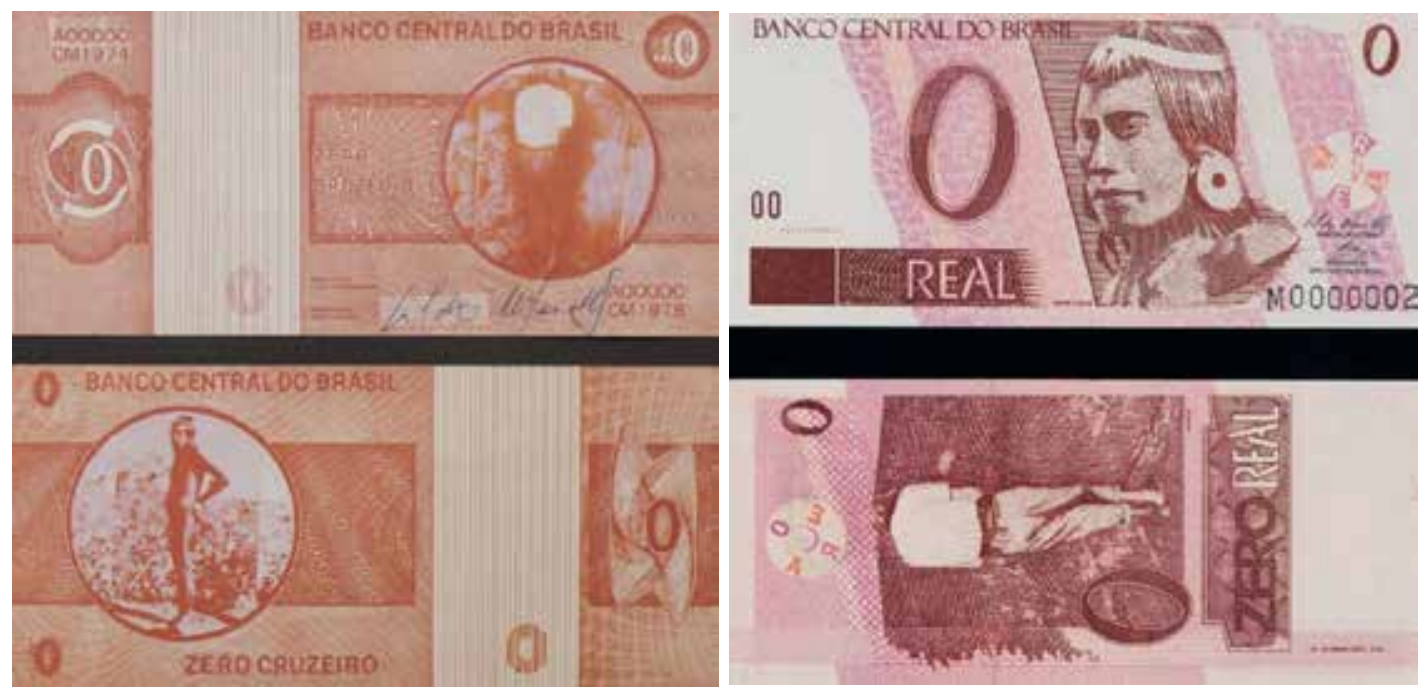

FIG 8 - Zero real, 2013, Cildo Meireles. Catálogo Cildo Meireles, Cosac Naify

"Sal sem Carne", proposição de Cildo de 1975, revela fatos históricos sobre um dos primeiros massacres indígenas a ser denunciado e averiguado como criminoso no Brasil. Trata-se de um disco de vinil, que possui 8 canais sonoros simultâneos. 4 destinados à cultura branca portuguesa e 4 relacionados à indígena. Em um dos canais da cultura branca, Cildo recorta o som de romarias que se contrapõem aos dos depoimentos de tribos indígenas onde um dos testemunhos apresenta o massacre expedido por fazendeiros na década de 1930: de um avião eles jogaram sobre uma aldeia, roupas contaminadas com vírus da gripe e bacilos da tuberculose. Essa tática, inclusive, é reutilizada atualmente, mas recorrendo à estratégia do envenenamento da água e de plantações. Pipocam notícias de jornal que nos informam como a disputa pela terra e suas riquezas se persevera à moda do século $\mathrm{XVI}$, em um ritmo incessante de extermínio.

\section{Considerações Finais}

Esse tempo presente ornado por traços de violência, que se repetem periodicamente, nos oferece um cenário apocalíptico, que aparentava ser distante e onírico, assombrado por fantasmas que nunca descansam. A superação da barbárie constitui-se na borda de um trajeto inalcançável. Damiela Eltit no texto "A máquina Pinoche$t^{\prime \prime} 8$, nos relembra que o ditador chileno Augusto Pinochet manifestou com maestria o terror, mas a violência não se retém apenas a uma face. $O$ conceito perdura e sobrevive através da reprodução de um modus operandi repressivo de sucesso. A retomada deste terror se dá pelo estado de crise - geralmente simulado - na convocação de uma mudança dita necessária, não raramente invocando ações de violência sem precedentes contra um pensamento, corpos, culturas divergentes, homogeneizando as diferenças e lavrando um terreno para que a amnésia da barbárie, floresça.

A alusão ao corpo interdito, roto e censurado, perpetua-se assim, na arte brasileira, por décadas. O bólide 22 Mergulho do Corpo caixa-poema 4 (1967) de Hélio

8 ELTIT, Diamela. "La máquina Pinochet" In Signos Vitales. Escritos sobre literatura, arte y política. Santiago: Ediciones Universidad Diego Portales, 2008. Pgs, $139-140$. 
Oiticica, uma caixa d'água cujas dimensões são incapazes de acolher a totalidade do corpo, nos convoca ou afirma? A caixa abriga, quando muito, nossos pés e mais certeiramente, nossa mirada que repousa na superfície translúcida da água e se estende ao fundo, por entre as letras negras da frase: "Mergulho do Corpo", onde avistamos tudo isso em fusão com o reflexo de nossa imagem. Esse mergulho raso, resultado de uma impotência, uma restrição ao movimento corpóreo, se assemelha à suspensão de Daniel Santiago como uma imersão interrompida, presa abismo. De ponta cabeça, escapa-nos o chão sobre nossos pés, mas acolhe logo acima dele, a chegada interminável do céu que não tardará em cair.

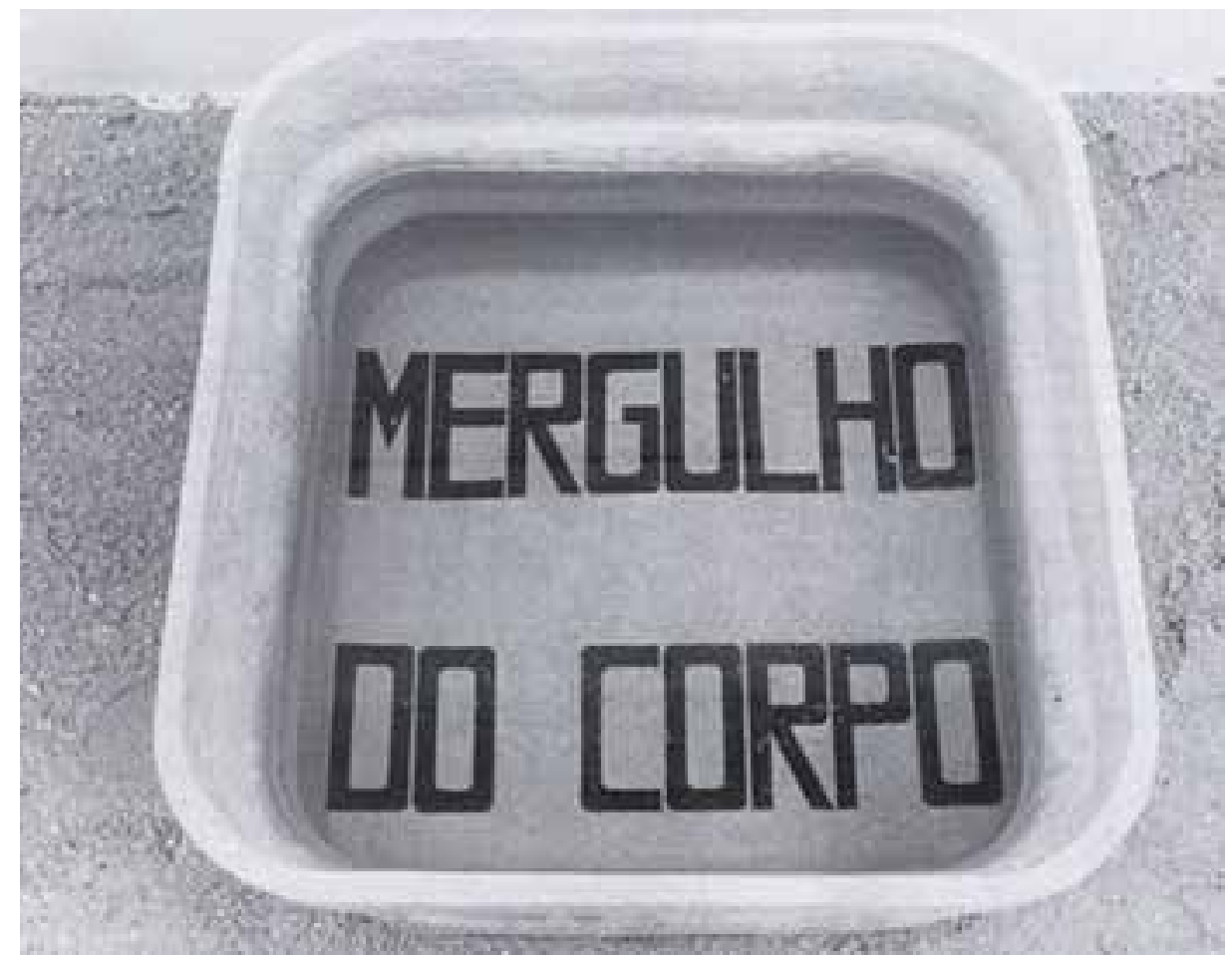

FIG 9 - Bólide 22 Mergulho do Corpo caixa-poema 4 (1967) de Hélio Oiticica. Disponível em: https:/li.pinimg.com/originals/ee/76/16/ee7616006a242d2d1d87ea82c8e4b52c.jpg. Acesso em 15 set. 2017.

Em 1976, Edgardo Antonio Vigo, artista argentino e um dos pioneiros da Arte Postal na América Latina, produz um carimbo da série Poemas Visuais que irá viajar os continentes. A frase, elaborada dentro do contexto de uma das mais sangrentas ditaduras sul-americanas, concretizou-se em apoio ao movimento Mães da Praça de Maio, que perderam seus filhos devido à perseguição política implacável exercida pelo Estado argentino. O trabalho nos deixa uma recomendação sobre o poder deste bem maior, que ora nos usurpam e que ora se perde pelo caminho: "Semear a memória para que não cresça o esquecimento". Este dever de lembrança, cabe também ao artista. 


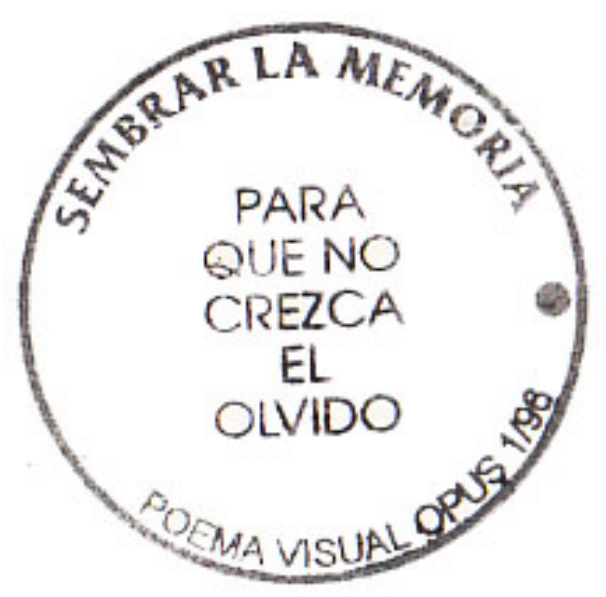

FIG 10 - Sembrar, Poema Visual. Edgardo Antônio Vigo, 1976. Disponível em: https://merzmail.files.wordpress.com/2009/07/sembrar.jpg. Acesso em 15 set. 2017.

\section{Referências}

ALBERT, B., MILLIKEN, W. Urihi A: A Terra-Floresta Yanomami. Instituto Socioambiental, São Paulo: 2009.

ANDUJAR, Cláudia. Marcados: Cláudia Andujar. São Paulo: Cosac\&Naify, 2009.

ARANTES, Paulo. Democracia de baixa intensidade militariza a gestão social Disponível em: http://www.boitempoeditorial.com.br/v3/news/view/3549 Acesso em: 08 Jun 2016. Entrevista.

BIRMAN, Joel. Arquivo e Mal arquivo: Uma leitura de Derrida de Freud. In Natureza Humana 10(1): 105-128, jan-jun. 2008.

CHIARELLI, Tadeu. Anna Bella geiger: outras anotações para o mapeamento da obra in ARS (São Paulo) vol.5 no.10 São Paulo, 2007.

CIIIP (Centro Internacional de Investigação e Informação para a Paz). O estado da paz e a evolução da violência: a situação da América Latina. Campinas: UNICAMP, 2002.

CASTRO, Eduardo Viveiros de. O recado da mata. In A queda do céu: palavras de um xamã yanomami. São Paulo: Cia das Letras, 2015.

DERRIDA, Jacques. Mal de Arquivo, uma Impressão Freudiana. Rio de Janeiro: Relume Dumará, 2001.

ELTIT, Diamela. La máquina Pinochet In Signos Vitales. Escritos sobre literatura, arte y política. Santiago: Ediciones Universidad Diego Portales, 2008. Pgs, 139-140. 
KOPENAWA, Davi; ALBERT, Bruce. A queda do céu. Palavras de um xamã yanomami. São Paulo: Cia das Letras, 2015.

MEIRELES, Clldo. Cildo Meireles. São Paulo: Cosac Naify, 2000

PIOVESAN, Flávia. Direito Internacional dos direitos humanos e lei de anistia. In O que resta da ditadura: a exceção brasileira. São Paulo: Boitempo, 2010.

Desarquivando o Brasil. Disponível em: http://www.desaparecidospoliticos.org.br/pagina.php?id=102\&m=5 Acesso em: 01 jun. 2016.

ROUILLÉ, André. A fotografia: entre o documento e a arte contemporânea. São Paulo: Ed. SENAC, 2009.

SAFATLE, Wladimir, TELES, Edson (org.). O que resta da ditadura: a exceção brasileira. São Paulo: Boitempo, 2010. 